\title{
Administración de la diversidad
}

\author{
Alicia Cristina Silva Calpa ${ }^{1}$ \\ Marilu Avendaño A ${ }^{2}$ \\ Julio Cesar Montoya R. ${ }^{3}$
}

\section{Resumen}

El desarrollo de la competencia intercultural tanto a nivel directivo como a nivel de los empleados de una organización es una exigencia cada vez más sentida, porque de ella se derivan la mayor cantidad de soluciones a los conflictos surgidos debido a los cambios de la globalización de las organizaciones, es por ello importante que se dispongan los medios y estrategias, que permitan el desarrollo de dicha competencia a todo nivel.

Uno de los mecanismos es por medio de la investigación de situaciones o casos exitosos, así como también la de juegos de roles, que conlleven planes de acción adaptados a cada situación presentada. La investigación de la realidad empresarial en momentos de cambios globales, permite que no solamente se conozcan las características diversas de la población objeto de estudio, sino que además se identifiquen sus repertorios de actuación y los mecanismos de interacción más idóneos.

No es suficiente contar con el conocimiento de la diversidad y patrones de conducta individual y grupal en una organización, es además imperioso generar estrategias de

\footnotetext{
${ }^{1}$ Administradora de empresas, especialista en Pedagogía para el Desarrollo del Aprendizaje Autónomo. Magíster en Sistemas de Calidad y Productividad.Estudiante de Doctorado de Administración de Negocios, mención Gerencia. Docente Universidad Nacional Abierta y Distancia - UNAD. alicia.silva@unad.edu.co.

${ }^{2}$ Administradora de Empresas, Especialista Gestión de Proyectos y en Educación Superior a Distancia, Magister en Educación. marilu.avendano@unad.edu.co

${ }^{3}$ Administrador de Empresas, Especialista en Pedagogía para el Desarrollo del Aprendizaje Autónomo, Maestría en Administración de Empresas.Docente de la Universidad Nacional Abierta y a Distancia - UNAD. julio.montoya@unad.edu.co
} 
articulación entre las personas y de ellas hacia los procesos globales, derivados de procesos de investigación de una realidad específica.

\section{Introducción}

Los efectos de la globalidad se ven a todo nivel tanto en el mundo de los negocios, de la educación, de la política y de las artes y van acompañados de gran movilidad de personas de unos lugares a otros e incluso su interacción por los diversos medios de comunicación. Dichos efectos globalizadores se caracterizan por altos matices de interacción multicultural y pluralista, ya que las dinámicas sociales no son estáticas, sino altamente fluidas y dinamizantes, hacia cambios cada vez más vertiginosos.

"En medio de este maremágnum de posibilidades de interacción se encuentra el ser humano con diversas opciones de interacción multicultural y ante las cuales no siempre se logran los objetivos buscados, debido al surgimiento de conflictos, por el indebido manejo de la diversidad cultural. "la organización se define como la interacción de múltiples agentes y procesos que responden a presiones del entorno en el que actúan, de donde surge y se desarrolla una alta capacidad de autoorganización” (Løwendahl y Revang, citado por Torres y Mejía, 2006, p. 125)

Cada cultura cuenta con su bagaje de recursos, denominados "repertorio", dichos recursos se componen de sus características, formas de ser y reaccionar, lenguaje, cultura, tradiciones, entre otros y donde cada recurso se desarrolla tanto por influencia de su cultural como por los matices de su propia personalidad. "El repertorio cultural constituye la suma del conjunto de opciones utilizadas tanto por un grupo de gente como por sus miembros individuales para la organización de la vida". (Even-Zohan, 2008) Es por ello 
que un repertorio en sí mismo diverso dentro de una misma cultura y fluye de acuerdo con los cambios de la misma, por ello es que surgen los conflictos a los cuales también se responde por medio del repertorio cultural el cual proporciona algunas alternativas para establecer en primer lugar el grado de interacción multicultural y la investigación de las situaciones específicas para la obtención de conclusiones aplicables a cada contexto y cultura específicas.

\section{La gestión multicultural}

La competencia intercultural implica "la disposición, por parte de la persona, de una serie de conocimientos, habilidades y actitudes [...] le permitirán relacionarse y superar los posibles retos y dificultades que puedan surgir debido a las interacciones culturales" (Aneas, 2002) La competencia intercultural implica la capacidad de manejar adecuadamente las diferencias para generar mayores niveles de aprendizaje en beneficio de todo el grupo.

Es importante reconocer que cada cultura tiene su propia escala de valores, sus gestualidades y formas de expresión, así como sus propios códigos de comunicación y normas de comportamiento y por ende construyen su propio imaginario de la realidad, por lo cual es importante investigar como en ellos la realidad y como la sienten, para determinar sus formas de actuación frente a los contextos laborales, teniendo en cuenta que las empresas tienden cada vez a incrementar su diversidad cultural e internacional.

"Muchos los gerentes tienen que ser capaces de interactuar efectivamente con personas de muy variada fondos, a menudo sólo por períodos breves de una 
negociación, un grupo de trabajo y con poco o ningún tiempo para adquirir conocimientos sobre las culturas" (Berthoin Antal, citado por Berthoin, 2003).

En los procesos interculturales se concibe al ser humano como un ser cultural complejo, compuesto de una variada gama de comportamientos, sentimientos, estereotipos, ideas, pensamientos, paradigmas, personalidades, imaginarios y diversas características, adquiridas tanto de una cultural como de su propio proceso de vida a nivel familiar, colectivo e individual, los cual lo lleva a concebir el mundo por medio de su propio cristal y a dar respuestas consecuencia de su repertorio de recursos ante la realidad encontrada. La importancia del desarrollo de las competencias intercultural por tanto sería el saber aprovechar todas las diferencias para ser concebidas como diversidades y por ende facilitar su dinamismo en beneficio del entorno y de todas las personas con diversas culturas que actúan en un mismo contexto por muchas razones.

"La diversidad cultural es el término utilizado para referirse al grado de variación cultural en ciertas áreas geográficas en las que co-existen diferentes culturas. En consecuencia, organizaciones como la UNESCO consideran que la diversidad cultural es patrimonio común de la humanidad y, por lo tanto, ha fijado políticas y estrategias favorables para la conservación y promoción de las culturas existentes" (Álvarez y Urbano, 2013, p. 156).

Uno de los mecanismos para promover la diversidad como una oportunidad, es la investigación de la riqueza cultural de sus miembros, ya que posterior al conocimiento surge la valoración tanto de lo propio como de lo ajeno, partiendo de la propia cultural, para realizar paralelos que no se queden en la mera comparación, sino que permitan ver las diversas formas de hacer las cosas, los puntos de confluencia y los puntos de divergencia, 
para establecer planes y programas de interacción, identificando habilidades, competencias y valores que permitan conocer los dinamismos y potencialidades de cada miembro diverso en la organización, en beneficio de los objetivos comunes.

No basta con el conocimiento teórico de los rasgos diversos y patrones de conducta de los empleados de una organización, es también imperioso desarrollar ejes de unión, puntos de articulación y espacios de convivencia en medio de la diversidad, por medio de la propuesta de enfoques y métodos para cada situación particular, la cual solo puede derivarse de procesos de investigación de una realidad específica.

Lograr la interacción cultural es un verdadero reto gerencial y de lograrse es una ganancia para todos los grupos de interés que la rodean, pero si no se logra puede ser de gran afectación tanto para la organización como para cada uno de sus miembros que pueden ver menoscabados sus aspectos culturales en beneficio de objetivos comerciales que a la larga no surtirán los efectos esperados, porque sería una organización que desconoce su riqueza interna intercultural.

Es por ello que más allá de proponer un proceso de solución de conflictos, se pueda partir de investigación de los enfoques culturales, pluralistas e interdisciplinarios. "La coexistencia de los sistemas sociales y culturales depende de su capacidad de adaptación, tolerancia e inclusión de las distintas culturas que subyacen en un mismo entorno" (Rodríguez, 2008, p. 496).

La cultura incluso entre miembros de una misma localidad difiere, debido a los aportes de la estructuración de su propia personalidad, los parámetros de crianza y los flujos de información individual y colectiva que dominan sus vidas, por ello la diversidad 
es más compleja que simplemente separar a las personas por grupos, es también todo aquello que hace parte de su pasado y de su presente, de la forma de ver la vida y de su forma de integrarse a un todo, es por ello que todo ser humano es único en esencia y complejo en su interacción.

“Una metáfora útil para la cultura es un iceberg, sólo una pequeña parte de la cultura es visible, tales como el comportamiento, rituales, símbolos y reglas escritas. Elementos visibles son una expresión de los supuestos culturales básicos, normas y valores”. (Citado por Berthoin, 2003). Aunque los aspectos que más se pueden observar en las diferencias culturales son diversos, son aún más diversos los aspectos que no se alcanzan a apreciar y la investigación sobre ellos hace que se pueda conocer y comprender las diversas formas de comportamiento, ante las variadas situaciones y como la diversidad de las culturas en un mismo grupo, puede aportar elementos para la generación de una consolidación multicultural social.

La complejidad del ser humano, se refleja a todo nivel, ya puede ser de un pueblo, de una organización o de una familia, porque aunque hermanos un grupo de personas, tienen formas diversas de ver la vida, de reaccionar a los acontecimientos y de expresar sus individualidades, por ello los diversos estudios sobre el hombre, siempre arrojarán que la situación con seres humanos, no puede arrojar datos exactos, sino datos diversos adaptables a diversas categorías de interacción que permiten que el ser humano no permanezca estático en el transcurso de la historia de la humanidad, sino que mediante su interacción con otros seres y con la naturaleza y todo lo que le rodea, pueda avanzar por sendas de múltiples saberes hacia cada vez nuevos descubrimientos, nuevas formas de comunicarse y nuevas formas de hacer las cosas. 
La administración de la diferencia y la gestión intercultural permite nuevas formas de comportamientos, nuevos códigos de interacción y nuevas formas de percibir la realidad, en torno a objetivos comunes establecidos, donde la cultura emergente influya en el comportamiento individual, así como influyen en el ser todas las culturas a las cuales pertenece. Aunque las diferencias individuales se den gracias a la complejidad del ser humano, las necesidades básicas de afecto y de ser parte de un grupo, de sentirse útil para un propósito y de ser reconocido, teniendo una identidad, un estatus y un lugar logrado, hacen que se conformen las culturas alrededor de ciertos patrones de comportamiento.

Los miembros que pertenecen a comunidades interculturales formadas por diversas necesidades, llevan consigo una gran diversidad y la posibilidad de generar mayores procesos de aprendizaje, entre todos sus componentes, pero a la vez las posibilidades de mayor presencia de conflictos, pero es la gerencia quien debe propiciar el desarrollo de la competencias intercultural, la cual debe incluir cualidades como la apertura, la flexibilidad, el trabajo en equipo, el liderazgo compartido, los juegos de roles, los valores y su diversidad, la conciliación, la articulación, entre otras cualidades y técnicas que permiten a todos los integrantes empezar a desarrollar mentalidades más globales y comprensivas de sus diversos entornos.

Cuando se dan los primeros pasos de diversidad cultural en los diversos grupos conformados, se presentan muy a menudo los conflictos y malentendidos interculturales, los cuales tienen su base en la diferencia, especialmente en el manejo de los valores. Es por ello que es importante aprender y adentrarse en las diversas formas culturales que permitan evitar los juzgamientos con solo conocer las situaciones de manera superficial y la investigación, los viajes y los intercambios son medios efectivos de conocimiento del otro. 
Pero es la investigación por excelencia el mejor método porque puede incluir diversos medios para el encuentro de sus resultados, sistematiza las situaciones encontradas y por sus resultados permite hacer proyecciones y aplicaciones de solución.

Los individuos no pueden ser fácilmente clasificados en grupos o subgrupos pertenecientes a una cultura determinada, desconociendo su complejidad, porque pueden ser parte de varias culturas al mismo tiempo, dependiendo de su origen, intereses y demás variables que hacen que una persona sea única en su personalidad y en su esencia.

Por ello se hace hincapié en la propuesta de proyectar los resultados de la investigación, hacia la búsqueda de la unidad en la diversidad, la cual pretende sobrepasar todos los límites y diferencias existentes, encontrando puntos de convergencia que permitan superar las barreras culturales, no asimilándose como tal, transformándolas de barreras a oportunidades, de acuerdo a los objetivos del grupo, al contexto y a las necesidades individuales, sin caer en la homogenización de las personas, lo cual atenta contra la individualidad, sino conociendo sus miradas, enfoques, historias de vida, gustos y preferencias, ideologías, formas de reaccionar a los eventos y en medio de ellos empezar a identificar que personas de culturas y personalidades totalmente diferentes, pueden encontrar anclaje en ciertos aspectos similares que las hace sentir parte de otros grupos, nuevos grupos diversos.

El enfoque de la investigación hace énfasis en los mecanismos por medio los cuales las personas puedan dejar los paradigmas culturales y llegar hacia una apertura de nuevas culturas, con nuevas interpretaciones de la realidad. Para lograrlo se necesita el desarrollo de competencias individuales y de grupo, el cual se considera es posible desarrollar debido a los momentos de globalización, donde las personas y las instituciones se ven obligadas a 
salir de sus fronteras, pero aun así es importante mantener los niveles de respeto y valoración por lo propio y lo ajeno, porque por otra parte surge la necesidad de mantener intactas las culturas, con el fin de preservar los legados ancestrales e históricos. Obviamente en medio de todo este proceso surgirán nuevas culturas alrededor de nuevos enfoques y nuevas formas de ver la realidad.

Aunque la influencia de las culturas es preponderante en los individuos también se encuentran las necesidades por el cambio, por hacer parte de otras culturas y por ende cada persona puede hacer parte de muchos grupos con diversidad de culturas y comulgar en ciertos aspectos con culturas totalmente diferentes. Debido a los medios de comunicación globales, también se han intensificado todos los procesos a nivel de los negocios, los estudios y a todo nivel y el ser humano se encuentra en una nueva dinámica que lo somete a procesos estresantes de desarrollo de más de una actividad a la vez y está en la necesidad de desarrollar nuevas competencias que le permitan hacer parte de las nuevas culturas emergentes.

En el modelo tradicional la diversidad ni siquiera se gestiona y se cuenta con etapas que pasan por la negación de la diferencia, la defensa de la diferencia, la reducción entre las similitudes hasta la aceptación de diferencia, la adaptación a otras culturas y la integración como una etapa avanzada de acuerdo intercultural, para la constitución de una sociedad multicultural y pluralista. Obviamente que el proceso para llegar a la constitución de una sociedad multicultural no es fácil y se presentan resistencias en la población receptora y en la población o miembros de una nueva cultura, concibiéndose en algunos casos como una amenaza para el sistema, como es el caso de las poblaciones desplazadas por la violencia que se ven obligadas a llegar a las grandes ciudades a ocupar los escasos servicios que ya 
han ganado los citadinos inicialmente, por ello el gobierno interviene por medio de reglamentaciones y programas de integración para dar acogida a las nuevas culturas, quienes deben desprenderse de gran parte de su forma de ser para poder adaptarse a su nueva forma de vida.

"Hemos acuñado el término "realidad de la negociación" para nombrar el proceso por el cual individuos generan una estrategia eficaz de la acción en una interacción intercultural haciendo a sí mismos y unos a otros conscientes de sus interpretaciones culturalmente en forma y las respuestas a una situación dada y ampliar su repertorio adecuadamente". (Citado por Berthoin, 2003)

En países latinoamericanos se ha dado la multiculturalidad no como un proceso voluntario sino que se ha propiciado por diversas situaciones sociales adversas, pero que al contrario de ser una mayor resistencia para la integración ha sido un punto de convergencia para un mayor entendimiento, ya que en medio del sufrimiento y el dolor, se encuentran muchos grupos identificados con situaciones similares vividas, como pueden ser: la violencia intrafamiliar y discriminación de la mujer, el trabajo forzado para niños, el reclutamiento forzado para la guerra, el despojo de sus tierras, la perdida abrupta de familiares, entre otras historias de vida que por su matiz de dolor, dejan huellas en sus integrantes y encuentran situaciones similares en personas de culturas totalmente diferentes, pero que los hace unirse para salir adelante.

\section{Conclusiones}

El concepto de la realidad de la negociación pretende que se logre una sociedad multicultural reconocimiento a todo ser humano igual en derechos, pero diverso en su 
cultura, con un propio repertorio de características individuales y grupales. Es por ello que aunque iguales en derechos todos los seres humanos somos diversos, con similitudes de acuerdo a las culturas compartidas y las experiencias vividas y con diferencias de acuerdo a los antecedentes culturales y ancestrales. El reto de los gerentes en tiempos de globalización es el desarrollo de competencias para la vivencia de comunidades multiculturales, para responder a sus necesidades y para hacer de sus visiones de vida, orientaciones hacia una misma cultura corporativa y con ello poder encontrar la propuesta Unidad en la Diversidad.

Una manera eficaz de manejar y negociar los conflictos en medio de la diversidad se basa en los procesos investigativos de la realidad, con el fin de identificar la propia cultura y las culturas visitantes y/o emergentes, que posibilite comprender las dinámicas culturales, las diversas formas de ver el mundo y las alternativas de solución que se pueden presentar, para beneficio común. El ser humano se redescubre cada día debido a que los cambios se aceleran por la integración multicultural y por ende los procesos de investigación de la realidad apoyan la solución de los conflictos y la búsqueda de alternativas de solución ante las problemáticas encontradas, por medio del repertorio de recursos multiculturales de cada uno de los miembros de una organización o grupo social.

Se reconoce a las personas como seres altamente complejos, derivados de su formación, de su historia de vida, de sus experiencias, de su cultura, los grupos a los que pertenece, sus características personales, sus competencias, habilidades, ideologías, entre otros y en medio de su complejidad interactúa actualmente en medios altamente complejos y pluralistas, que lo obligan a buscar nuevas formas de hacer las cosas para mantenerse vigente en un mercado altamente cambiante, al cual quiere seguir perteneciendo porque 
aunque la cultura cambie, la necesidad de hacer parte de un grupo y de ser reconocido es inherente al ser humano. Por ello la imperante necesidad de los gerentes y administradores de grupos de desarrollar la competencia intercultural, la cual incluye la capacidad de aprovechar la diversidad de recursos culturales para beneficio común y de cada uno de sus integrantes, haciendo de la diversidad una oportunidad.

\section{Referencias}

Álvarez, C; Urbano, D; (2013). Diversidad cultural y emprendimiento. Revista de Ciencias Sociales (Ve), XIX(1) 154-169. Recuperado de http://www.redalyc.org/articulo.oa?id=28026467004

Aneas, A.M. (2002). Competencia intercultural, concepto, efectos e implicaciones en el ejercicio de la ciudadanía. Facultad de pedagogía. Universidad de Barcelona, España. Recuperado de http://www.rieoei.org/deloslectores/920Aneas.PDF

Berthoin, A.A y Fredman, V. Negociación realidad como un enfoque para Competencia Intercultural. SP III 2003-101. ZITIERWEISE / MENCIÓN. Negociación realidad como un acercamiento a la competencia intercultural. Documento de debate SP III 2003-101. Wissenschaftszentrum Berlín für Sozialforschung (2003)

Even-Zohar, I. (2008). La fabricación del repertorio cultural y el papel de la transferencia. Madrid, Arco Libros. P: 217-226. http://www.tau.ac.il/ itamarez/works/papers/trabajos/EZ-Fabricaccion-delrepertorio2008.pdf 
Rodríguez Pérez, M C; (2008). El reto de la gestión humana frente a la complejidad y pluralidad cultural. Revista Venezolana de Gerencia, 13(43) 492-506. Recuperado de http://www.redalyc.org/articulo.oa?id=29004309

Torres Valdivieso, S; Mejía Villa, A H; (2006). Una visión contemporánea del concepto de administración: revisión del contexto colombiano. Cuadernos de Administración, 19(32) 111-133. Recuperado de http://www.redalyc.org/articulo.oa?id=20503205 